\section{Ueber Glycerin als Unterscheidungsmittel geformter und ungeformter Fermente. Von}

Dr. Carl Weigert,

I. Assistenten am patholog. Institute zu Breslau.

Man versteht bekanntliclı unter Fermenten diejenigen Agentien, welche bei einer sehr geringen Menge ihrer Substanz sehr erhebliche chemische Umsetzungen liewerkstelligen. Solche Fermente sind z. T. eigentlich chemische Stoffe z. B. die Verdauungsfermente. Diese stamnen wohl sämmtlich von bestimmten Zellen lıer, sie können jedoch auch ıach Tödtung ihrer Erzeuger, die ja imınerhin loch organisirt und gegen äussere Einflüsse sehr empfindlich sein können, ihre Wirksamkeit beibehalten. Aus diesem Grunde nennt man sie unorganisirte oder ungeformte Fermente. Ilınen gegenüber stehen die sogenannten geformten oder organisirten Fermente, d. l. diejenigen bei denen der Lebensprocess kleiner Organismen zur Herstellung der Fermentwirkung erforderlich ist. Zu diesen Fermentwirkungen gehört die Fäulniss, die Alcohol-Gährung etc. Wenn auch bei diesen Fermenten die Wirksamkeit im chemischen Sinne ebenso unklar ist, wie bei den andern, so ist es hier wenigstens einigermassen verständlich, warum so geringe Mengen zur Erregung grosser Wirkungen genügen. Die kleineren Mengen haben ja die Fäligkeit sich in der Flüssigkeit, die die Zersetzung erleidet, durch Erzeugung ueuer Organismen ausserordentlich zu vermehren, so dass die lineingebrachte Fermentnasse gar nicht der wirklich in Action tretenden entsprieht.

So scharf aber auf den ersten Blick der Unterschied zwischen diesen beiden Fermentformen zu sein scheint, so sehr verwischt sich derselbe bei näherem Zusehen und zwar für diejenigen Fälle, bei denen die Fermentwirkungen allerdings von lebenden kleinsten Organismen ausgehen, aber nicht direct von den Lebensäusserungen dieser abhängen. Das ist dann der Fall, wenn die kleinen Wesen erst ilırerseıts ein chemisch wirkendes (ungeformtes) Ferment erzeugen. Sie verhalten sich also dann genau so, wie die Magenzellen etc. und die Fermentwirkung kann auch nach Ertödtung des erzeugenden Organismus fortbestelıen. -

Mit den Gährungsund Fäulnissprocessen hat man aber schon seit langer Zeit die Infectionskrankheiten verglichen, ganz besonders aus dem Grunde, weil auch hier minimale Mengen eines in den Organismus eingefülırten Stoffes sehr mächtige Wirkungen hervorzurufen vermögen. Für diese Processe ist ebenfalls entsprechend den obengemachten Auseinandersetzungen die Frage nach der organisirten oder nicht organisirten Beschaffenheit des inficirenden Agens aufgetaucht und hat zu vielen Streitigkeiten Veranlassung gegeben. Auch hierbei ist aber die Frage complicirt durch den Umstand, dass ja die Krankheitsgifte möglicherweise solche chemische Stoffe resp. Fermente sein können, bei denen jene kleinen Organismen nur als Erze uger derselben in Action treten. Die Frage wird dann hesonders interessant, wenn das Krankheitsgift nicht nur seine Wirksamkeit in dem angesteckten Organismus entfaltet, sondern in diesen auch neu erzeugt resp. vermehrt wird. Dieser Umstand ist für den Fall leicht erklärlich, wenn das eingeführte Agens ein Organismus ist, begabt vor allem eben mit der Fähigkeit der Fortpflanzung, wäre aber ungemein dunkel, wenn es sich sicher nachweisen liesse, dass ein miteingeführtes lebendes Wesen hierfür nicht nolhwendig sei. Man hat nun den Nachweis der chemischen Natur gewisser infectiöser Stoffe (mochten diese sich im Körper neu erzeugen oder nicht) auf verschiedenen Wegen zu führen versucht. Einen dieser Versuclıe, die Organismen von den anhaftenden "fremden" Fermenten zu befreien und sie so unschädlich zu machen habe ich bereits mehrfach besproclien'), der andere bestelit darin, dass man die Organismen zu tödten versucht und die nunmehr leblosen „Fermente“ auf ihre Schädlichkeit prüft.

Bis vor einiger Zeit hielt man es für ein leichtes durch wenig energische Mittel, die also die chemisch wirkenden Fermente nicht an-

y) U. a. auch in einem Aufsatze "Zur Bacterienfrage* (Berl. Kl. Woch 1877,18 ). In diesem Aufsatz sind dadurch, dass ich die. Korrectur nicht selbst besorgen konnte, eine Anzahl Druckfehler stehen geblieben, deren Rectiflcirung aus Gründen der Redaction unterblieb. Es schein mir jedoch nöthig wenigstens einen Satz zu corrigiren, der durch eine kleine Aenderung einen zu speziellen Sinn bekommen hat. S. 18 muss es heisen: Billoth hat gezeigt, dass beim Ueberpflanzen ron Bacen in: Bill terien in eine Nãhrflüssigkeit die Bacterlen die Eis
können in einer anderen sich wieder zu vermehren. griffeu, die dahei vorkommenden Organismen zu tödten. Man hatte gefunden, dass einfaches Kochen, ja eıne Erhitzung auf $60-80^{\circ}$ schon hiureiche die gewölınlichen Fäulnissorganismen zu vernichten. Daraus schloss man dann, dass diese Temperatur auch genügen müsste, um alle anderen Dinge, denen man den Namen von Bacterien gegeben hatte, abzutödten. Diese Zeıten alıer, in denen man olıne weiteres die Erfahrungen, die man bei der oder jener Bacterienform gefunden hatte, auf alle andern ülsertrug, sind glücklicherweise vorüber. Schon vor einigen Jahren hatte man gefunden, dass die Siedhitze nicht im Stande sei, alle diese unter gemeinschaftlichen Namen zusammengelassten kleinen Wesen zu vernicliteu und in neuerer Zeit hat sich besonders durch Untersuchungen von $\mathrm{C}_{0} \mathrm{~h} \mathrm{n}$ herausgestellt, dass manche Keime derselben z. B. die Sporen der Bacillen des Ileuinfuses, ungemein lange die Siedhitze zu ertragen vermögen. Man hat aber auch demzufolge alle Ursache mit den chemischen Agentien, denen man eine Ertödtung der "Bacterien" elc. zuschreibt, vorsichtig zu sein, zumal man diejenigen Stoffe, dıe die meisten organischen Körper ganz energisch zerstören, z. B. concentrirte Mineralsäuren, nicht in Anwendung ziehen kann. Diese letzteren würden ja auch jene unorganisirten organischen Stoffe, Fernente etc. zu Gruude richten und so ein Experimentiren mit diesen unmöglich machen. -

Es ist nun eine allbekannte Thatsache, dass die Impflymphe ihre Wirksaukeit auch beibehält, wenn sie mit verhältnissmässig beträchtlichen Mengen Glycerin versetzt ist. Sie bewirkt dann nicht nur eine Localerkrankung, sondern an der Iupistelle kommt es sogar zu einer sehr ergiebigen Vermehrung des Krankheitsgiftes. Würde man nun nachweisen können, dass das Glycerin die Bacterien und ihre Keime sicher zerstört so wäre damit die Frage entschieden, dass das Vaccinegift zu seiner Wirkung und Erzeugung keines lebenden Microorganismus bedarf, es wäre damit ferner gezeigt, dass ein unorganisirtes Ferment in einem fremden Orgauismus, der sonst nie einen derartigen Stoff erzeugt, sich zu vermehren im Stande wäre.

Einem oberfläcllichen Beobachter könnte diese Frage in der That entschieden scheinen. Das Glycerin, welches in geringer Beimischung fur die Erzeugung kleiner Wesen allerdings unschädlich ist, ist in hohen Concentrationen ein anerkannt conservirendes Mittel, welches 2. B. eine Fäulniss-Bacterienentwicklung in den damit versetzten Flüssigkeiten nich aufkommen lässt, ja sogar eine bestehende Fäulniss sistirt; es ist ein Mittel, welches (immer von gewissen Concentrationen ab) viele kleine Organismen zu tödten vermag (z. B. Hefe).

Diese einfachen Thatsachen beweisen aber noch nichts. Die Sistirung der Bacterienentwicklung resp. Fäulniss könnte schon darauf beruhen, dass die Fäulnissbacterıen sich im Glycerin nicht zu vermehren vermöchten, eine Tödtung derselben brauclite aber noch nicht zu erfolgen - ebensowenig wie die Fäulnisskeime durch reines Wasser getödtet zu werden brauchen, trotzdem sie in diesem sich nicht fortzuentwickeln vermögen. Es könnte aber auch immerhin möglich sein, dass auch die Fäulnissorganismen, gerade wie die Hefe etc. durch starke Glycerinmischungen in der That abstürben. Daraus würde aber noch lange nicht folgen, dass alle andern derartigen Wesen oder deren Keime ebenfalls von Glycerin zu Grunde gerichtet würden. Wenn es vielmehr gelänge zu zeigen, dass auch nur gew isse K e ime durch diesen Stoff selbst, bei beträclttlicher Concentration nicht zerstört werden, so würde für alle diejenigen Stoffe, in denen das Gift nocht nicht isolirt dargestellt ist, das Glycerin nicht mehr zur Entscheidung über die organisirte oder nicht organisirte Beschaffenheit desselben dienen können. Man könnte ja eben nirht wissen, ob die hierbei thätigen (hypothetischen, mikroscopisch eventuell nicht nachweisbaren) 0rganismen nicht in einer resistenten Form oder Art vorhanden wären Ich habe nun eine Heihe von Versuchen über diese Frage angestellt, die deshalb wichtig erschien, weil in der That jener obenerwähnte Schluss aus der Wirkung mit Glycerin versetzter Stoffe, besonders der Vaccinelymphe, gezogen worden ist.

Das Princip dieser Versuche ist sehr einfach. Es braucht nur nachgewiesen zu werden, dass Keime, die längere Zeit in einer concentrirten Glycerinmischung gelegen haben (so dass diese Zeit gehabt hat, ihre eventuell schädliche Wirkung zu entfalten), wenn sie in eine glycerin arme neue Nährflüssigkeit gebracht werden, sich zu vermehren vermögen. Damit wäre der Beweis geliefert, dass die glycerinreichen Lösungen zwar kein giinstiger Boden für die Wucherung der Organismen sind, dass diese aber in ihnen ihre Fortpflanzungsfahigkeit nicht verloren. haben, also nicht todt sind. Bei diesen Experimenten sind aber zweierlei Bedingungen zu erfüllen: einmal muss man voraussetzen können, dass die mit Glycerin behandelten Keime in der neuen Nährflüssigkeit günstige Bedingungen für ilıre Fortentwicklung finden, zweitens aber müssen bei der Uebertragung in diese Nährflüssigkeit alle fremden Keime sicher abgehalten werden.

ad 1. Nicht jede Nährflüssigkeit, die überhaupt Bacterien zur Vermehrung bringt, ist geeignet jed e übergepflanzte Bacterienform zur Entwicklung kommen zu lassen. Es bestehen in dieser Beziehung die merkwürdigsten 2. Th. noch unaufgeklärten Unterschiede, die namentlich in dem bekannten Billroth'sclıen Werke erwähnt sind. Für den vorliegen- 
den Zweck galt es daher eine Nährflüssigkeit zu benutzen, von der man sicher voraussetzen konnte, dass in ihr die hineingebrachten, schwer zerstörbaren Keime zu züchten wären. Als solche benutzte ich zuerst Heuinfus, in welches ich die Sporen von Henbacillen brachte. Späterhin habe ich es vorgezogen, eine Lösung des Liebig sclien Fleischextracts und als Keime die auf diesem gezüchteten Bacillensporen anzuwenden. Diese letztere Flüssigkeit ist nämlich viel leichter zo desinficiren, als dies oft beim Heuinfus der Fall ist, wie wir bald besprechen werden. Sie empfiehlt sich ferner durch die Zeitersparniss bei der Bereitung desselben, da die Darstellung des Heuinfuses stets mehr als eine Stunde erfordert. Ausser der richtigen Wall der Flüssigkeit kam es noch darauf an, eine gewisse Menge Luft in die Versuchsgefässe einzuschliessen, da sonst die Bedingungen für dıe Entwicklung der neuen Organismen möglicherweise nicht giinstig genug waren. Endlich durfte von dem Glycerinsporengemisch nur soviel zu der Nährflüssigkeil hinzıkommen, dass die neue Misclunng nicht etwa selbst eine so starke Glycerinlösung darstelle, dass auch in ihr die Entwicklung der Organismen unmöglich war. Wir werden im folgenden sehen, wie auch diese Bedingung erfüllt wurde

ad 2. Zur Vermeidung der Beimischung fremdartiger Keime musste die Nährflüssigkeit zunächst selbst desinficirt sem. Sie wurde (filtrirt und einmal durchgekocht) in Kölbchen von $20-25 \mathrm{Ccm}$. Inhalt gebracht, so dass etwa $2 / 3$ des Kölbchens erfïllt waren. Die Kölbchen waren vorher sorgfailtig ausgeglüht.

Nach dem Einfüllen der Flüssigkeit wurde der Hals des Kölbchens in eine capillare Röhre ausgezogen, diese unter einem spitzen Winkel umgebogen und ihr freses Eude zugeschmolzen. Die Capillare durfte nicht zu dünn sein, weil sie sonst beim Umbiegen leicht einknickte und undurchgängig wurde, sie durfte auch nicht zu dick sein, weil sonst bei der bald zu beschreibenden Procedur des Einlassens der Glycerinmischung zu viel von letzterer in das Kölbchen einströmte und so die Entwicklung der Keime durch zu reichliohe Beimischung von Glycerin unmöglich machte. Die Dimensionen der Capillare durften auclı aus dem Grunde niclıt zu bedeutend sein, weil sonst das später erforderliche Abschmelzen derselben nicht leicht genug vorzunehmen war.

So war denn der Inhalt der Kölbchen zunächst vor jeder ferneren Berührung mit der umgebenden Luft etc. geschützt. Er bestand aus der Nährfluissigkeit und einem Quantum Luft, welche durch die Erhitzung des Kolbenhalses beinı Auszielıen desselben in einem verdinnten Zustande sich befand.

Von solchen Kölbchen wurde eine Anzahl (gewöhnlich sechs) in einen hohen mit Wasser gefüllten Top gesetzt, an dessen Boden sie durch eine einfache Vorrichtung festgebalten wurden, so dass sie weder schwammen noch sicl umlegten. Das Wasser stand weit über den oberen Enden der Kölbchen. Es wurde dann zum Sieden gebracht und 3-6 Stunden springend kochend erhalten. Auch das verdampfende Wasser wurde immer durch bereıt gehaltenes kochendes ersetzt, so dass das Sieden niemals unterbrochen wurde. Es muss bemerkt werlen, dass nicht alle Glassorten ein so langes Erhitzen in Wasser ertragen. Manche bekommen feine Sprünge und sind daher zu diesen Versuchen unhrauchbar. - Die so znbereiteten gekochten kölbchen wurden nun umgekehrt in mit Glycerin gefüllten Bechergläsern 8 Tage im Brütofen gehalten und nur, wenn die makroskopische Untersuchung aller und die mikroskopische eines oder einiger eine Bacterienentwicklung ausschloss, zu den eigentlichen Versuchen verwendet. 